\title{
A TECNOLOGIA DE COMUNICAÇÃO DIGITAL NA FORMAÇÃO INICIAL DE PROFESSORES: CONCEPÇÕES, PRÁTICAS E CONTROVÉRSIAS
}

\author{
DIGITAL COMMUNICATION TECHNOLOGY IN INITIAL TEACHER \\ EDUCATION: CONCEPTIONS, PRACTICES AND CONTROVERSIES
}

\author{
Francieli Motter Ludovico ${ }^{1}$, Jaqueline Molon ${ }^{2}$, Aline Dubal Machado ${ }^{3}$, \\ Patrícia da Silva Campelo Costa Barcellos ${ }^{4}$, Sérgio Roberto Kieling Franco ${ }^{5}$
}

\begin{abstract}
RESUMO: A Tecnologia de Comunicação Digital (TCD) impacta diretamente na educação, logo, faz-se necessário pensar na formação de professores baseada no seu uso, para que sejam capazes de explorá-la e ir além da transposição. O objetivo deste estudo é compreender como acontece a integração da TCD na formação inicial de professores, partindo das concepções e atuações dos formadores. Assim, professores de dois cursos de licenciatura responderam a um questionário. Através do método da análise de conteúdo, os dados revelaram controvérsias. Os docentes têm consciência dos motivos para usar TCD, utilizam-na como recurso em algumas práticas, porém, nem sempre acontecem discussões e reflexões sobre seu uso e relevância. Evidencia-se a necessidade de vivenciar, refletir e dialogar sobre TCD, durante a formação inicial, construindo conhecimento para futura atuação. Logo, a universidade tem o papel de contemplar tais requisitos, a fim de possibilitar que a integração da TCD tenha um reflexo significativo posterior.
\end{abstract}

PALAVRAS-CHAVE: Licenciatura; Tecnologia de Comunicação Digital; Práxis pedagógica;

ABSTRACT: Digital Communication Technology (DCT) directly impacts on education, so it is necessary to think about teacher training based on its use, so that they are able to explore it and go beyond transposition. The aim of this study is to understand how the DCT integration happens in the initial teacher education, starting from the teacher's conceptions and practices. Thus, teachers from two Teaching Major programs answered a questionnaire. Through the content analysis method, the data uncovered controversies. Teachers are aware of the reasons for using DCT and they use it as a resource in some practices, however, discussions and reflections on its use and relevance do not always happen. Therefore, the need to experience, reflect and dialogue about DCT during the initial training is evident, to build knowledge for future performance. Like this, the university role is to contemplate such requirements, in order to allow the DCT integration to have meaningful results.

\footnotetext{
${ }^{1}$ Doutoranda em Informática na Educação na UFRGS; Mestre em Letras; Licenciada em Letras. Professora da Universidade Tecnológica Federal do Paraná - UTFPR-DV. A autora possui apoio e o fomento da UTFPR.

${ }^{2}$ Doutoranda em Informática na Educação na UFRGS; Mestre e Licenciada em Matemática. Professora do Instituto Federal de Educação, Ciência e Tecnologia do Rio Grande do Sul - IFRS. A autora possui apoio e o fomento do IFRS.

${ }^{3}$ Doutoranda em Informática na Educação na UFRGS; Mestre em Distúrbios da Comunicação Humana; Graduada em Educação Especial. Professora de Língua Brasileira de Sinais do IFRS. A autora possui apoio e o fomento do IFRS.

${ }^{4}$ Doutora em Informática na Educação e em Linguística Aplicada; Mestre em Letras; Licenciada em Letras. Professora do Programa de Pós-Graduação em Informática na Educação e do Instituto de Letras - UFRGS.

${ }^{5}$ Psicólogo, Mestre e Doutor em Educação, professor do Pós-Graduação em Informática na Educação, em Educação e da Faculdade de Educação - UFRGS.
} 
KEYWORDS: Major Programs; Digital Communication Technology; Pedagogical Praxis.

\section{Considerações Iniciais}

Na Sociedade da Informação (SI) é praticamente impossível conceber uma vida desprovida de recursos tecnológicos e que desconsidere a Tecnologia de Comunicação Digital (TCD). Coll e Monereo (2010, p. 20) definem a SI como "um novo estágio de desenvolvimento das sociedades humanas, caracterizado, do ponto de vista das TIC, pela capacidade de seus membros para obter e compartilhar qualquer quantidade de informação de maneira praticamente instantânea". Vive-se na época em que praticamente qualquer informação pode ser obtida em segundos através de uma breve pesquisa a sites de busca na internet, inclusive usando comandos de voz para tanto (ROJO, 2017; LUDOVICO; COSTABARCELLOS, 2019).

Como consequência, cada vez mais é crucial que as pessoas desenvolvam competências que lhes possibilitem usar esses recursos tecnológicos de forma consciente e crítica. Assim, já não é mais preciso argumentar que a TCD deve ser incorporada às práticas educacionais. Apesar disso, é importante promover discussões acerca das possíveis formas de incorporação da TCD no ambiente escolar, de modo a explorar todo o seu potencial educativo e auxiliar os estudantes a desenvolverem tais competências.

No entanto, na busca pela conquista desse ideal alguns desafios se impõem. Pode-se citar aspectos relacionados com a infraestrutura das escolas, por exemplo (CGI.br, 2019). Além disso, uma preocupação emergente refere-se à formação dos professores. Um dos desafios encontrados na comunidade acadêmica é prover a oferta de TCD, de modo que venha despertar, motivar e embasar o processo de ensino e aprendizagem dos professores em formação, para que esses consigam se constituir como futuros formadores, os quais possam fazer uso de recursos tecnológicos em prol de uma educação mais condizente com a demanda social e a inovação presentes no cotidiano.

Concebe-se a formação de professores como um continuum que exige constante atualização para que a prática pedagógica do formador consiga fomentar vivências e reflexões acerca da ação de como ensinar e de que forma esse processo poderá apoiar os discentes em seus caminhos individuais de construção de conhecimento. Desse modo, para permear essa práxis educacional acredita-se ser importante conhecer como os docentes formadores, 
atuantes em cursos de licenciatura, estão fazendo uso da TCD na formação inicial de professores com a finalidade de oportunizar formação, reflexão e conhecimento para as futuras práticas pedagógicas desses profissionais.

Assim, sustentada pela abordagem qualitativa, a presente pesquisa teve como objetivo averiguar o papel da TCD na formação inicial de professores atribuído pelos docentes formadores atuantes em dois cursos de licenciatura (em Letras e em Matemática) oferecidos em uma instituição federal da região sul do país. Adotou-se como instrumento de coleta de dados um questionário contendo seis questões abertas focadas nas práticas desses docentes, a fim de levantar as concepções e descrições de usos que eles faziam (fazem) da TCD em suas aulas. Os professores atuantes nos referidos cursos foram convidados, por e-mail, a participar da pesquisa, sendo obtido retorno de 11 docentes, os quais aceitaram participar do estudo.

Esse artigo estrutura-se em seis (06) seções. Após as considerações iniciais, traça-se uma discussão teórica acerca da formação inicial de professores para o uso da TCD, buscando embasamento tanto em orientações e normativas educacionais, quanto em autores que evidenciam seu potencial para a promoção de práticas pedagógicas significativas. Na sequência o percurso metodológico é delineado. Na análise de dados optou-se por apresentar considerações a partir de cada uma das perguntas respondidas pelos professores participantes do estudo, tendo em vista que as mesmas foram pensadas considerando possíveis entrelaçamentos nas respostas. Essa estratégia possibilitou o cruzamento de informações acerca das declarações dos professores nas diferentes questões, procurando compreender de forma ampla suas concepções em relação à integração da TCD ao longo da formação inicial de professores e apontamento de possíveis controvérsias que permeiam essa temática.

\section{Formação Inicial de Professores para o uso da TCD}

A discussão referente a como se pode integrar, efetivamente, a Tecnologia de Comunicação Digital (TCD) nos processos educacionais permanece atual. Pesquisas sobre o uso da TCD, por professores ou alunos, nas escolas brasileiras, como a TIC Educação, têm sido publicadas desde 2010, anualmente, pelo Centro Regional de Estudos para o Desenvolvimento da Sociedade da Informação (Cetic.br) e, embora de forma lenta, a integração das tecnologias na educação tem ocorrido (KENSKI, 2015).

A TCD está proporcionando muitas transformações na educação, considerando um novo perfil de aluno, apesar de enfrentar obstáculos como a falta de infraestrutura das escolas 
ou o pouco investimento do poder público, que ocasionam usos limitados e muitas vezes de baixa qualidade dos recursos disponíveis (CGI.br, 2019). Contudo, é fundamental "garantir aos jovens, aprendizagens para atuar em uma sociedade em constante mudança, prepará-los para profissões que ainda não existem, para usar tecnologias que ainda não foram inventadas e para resolver problemas que ainda não conhecemos" (BRASIL, 2018 p. 473).

Os estudantes de hoje, em sua maioria, são Nativos Digitais, que conforme Prensky (2001; 2010) são aqueles nascidos em meio à cultura digital e os quais têm contato com aparatos tecnológicos desde pequenos, possuindo uma maneira diferente de pensar, aprender, ser multitarefa, assim com lidar com hipertexto e interatividade. Prensky (2010) ainda explica que devido às constantes mudanças da realidade do estudante fora da escola, para poder prepará-los para seus futuros, não se deve concentrar apenas na mudança da tecnologia, mas em chegar à aprendizagem de uma nova maneira, onde cada um assume um novo papel. Os estudantes precisam se concentrar em usar novas ferramentas, encontrar informações, construir sentidos e criar, já os professores devem questionar, treinar e orientar, fornecendo contexto, garantindo rigor, significado e qualidade.

Essas competências estão presentes na Base Nacional Comum Curricular (BNCC), documento normativo que estabelece o conjunto "de aprendizagens essenciais que todos os alunos devem desenvolver ao longo das etapas e modalidades da Educação Básica” (BRASIL, 2018, p. 7). A BNCC abrange aspectos inerentes à integração da TCD nas práticas escolares ao longo de toda a educação básica e em todas as áreas do conhecimento. O referido documento aponta que compreender, criar e utilizar as tecnologias digitais concerne a uma das competências gerais da educação básica e salienta que seu uso deve ocorrer "de forma crítica, significativa, reflexiva e ética nas diversas práticas sociais [...] para se comunicar, acessar e disseminar informações, produzir conhecimentos, resolver problemas e exercer protagonismo e autoria na vida pessoal e coletiva" (BRASIL, 2018, p. 9).

Dessa forma, cabe aos professores pensar e propor as mais adequadas estratégias de uso da TCD de acordo com suas realidades como forma de auxiliar os estudantes a desenvolverem capacidades que lhes possibilitem utilizar esses recursos de forma crítica e consciente, sendo que, na era digital, compreende-se que "ajudar a se educar é o objetivo e a tarefa central do docente" (PÉREZ GÓMEZ, 2015, p. 141). Para tanto, é importante, primeiramente, não usar a tecnologia por si só, mas incorporá-la adequadamente (EADY; LOCKYER, 2013) e, assim, superar o uso de recursos tecnológicos “a serviço de uma prática 
letrada de ensino de um para muitos, que 'transmite' conhecimento a um receptor almejado como passivo e com o ‘conteúdo' sob controle do professor” (ROJO, 2017, p. 8). Possibilitar, assim, multiletramentos que de acordo com Rojo (2017, p. 4):

\begin{abstract}
são as práticas de trato com os textos multimodais ou multissemióticos contemporâneos - majoritariamente digitais, mas também impressos -, que incluem procedimentos (como gestos para ler, por exemplo) e capacidades de leitura e produção que vão muito além da compreensão e produção de textos escritos, pois incorporam a leitura e (re)produção de imagens e fotos, diagramas, gráficos e infográficos, vídeos, áudio etc.
\end{abstract}

Dessa forma, oferecer práticas de multiletramentos nos cursos de formação inicial de professores, significa direcionar o trabalho para que esses futuros protagonistas do ensino consigam desenvolver suas práticas compreendendo e, também, possibilitando tais aspectos. Com esse enfoque, foi publicada uma resolução pelo Conselho Nacional de Educação $\left(\mathrm{CNE} / \mathrm{CP} \mathrm{n}^{\circ} 2\right.$ de 20 de dezembro de 2019) que define as novas Diretrizes Curriculares Nacionais (DCN) para a Formação Inicial de Professores da Educação Básica. Diferente da anterior que estava vigorando desde 2015, a atual evidencia esse papel das tecnologias, traz orientações e estabelece competências gerais que devem ser desenvolvidas ao longo da formação inicial de professores, inclusive voltadas à sua integração no ensino de forma crítica, significativa, reflexiva e ética (BRASIL, 2019).

Percebe-se, nesse sentido, a realização de esforços para que a formação inicial de professores considere as novas exigências que a SI imprime, mesmo que indiretamente, sob as novas formas de ensinar com a incorporação dos recursos tecnológicos. Esses podem ser considerados como ferramentas para efetivação ou alcance de um objetivo pedagógico e não apenas como outra metodologia de exposição de conteúdo. Assim, "para usar das TCD a favor da aprendizagem, essas devem ser centrais na formação docente. Os momentos de reflexão docente, apesar de muitas vezes serem esperados, não devem ser um espaço para simples execução de receitas” (LUDOVICO, COSTA-BARCELLOS, 2019, p.8).

A TCD exerce grande influência nas ações em nossa sociedade, fazendo parte de nossa rotina, potencializando a autonomia dos sujeitos e formas diversificadas de aprendizagem, e alinhadas a isso têm-se as ferramentas tecnológicas. Essas podem auxiliar oferecendo oportunidades de interação nos contextos de ensino e aprendizagem. Dessa forma, a TCD pode servir como instrumento que auxilie a ação docente, a partir de práticas pedagógicas que beneficiam a aprendizagem em variadas áreas de formação. Assim, os docentes formadores frente à prática pedagógica com os futuros professores, ao fazerem uso 
dos recursos tecnológicos como ferramentas para efetivação ou alcance de um objetivo pedagógico, podem possibilitar interações que venham a viabilizar e auxiliar no processo de aprendizagem.

$\mathrm{Na}$ formação de professores, para alinharmos a teoria com a prática faz-se necessário entender o processo reflexivo que embasa as ações pedagógicas, neste caso específico, como a práxis ocorre através do uso da TCD. Essa perspectiva se embasa em Schön (2000), o qual apresenta a visão de que para conhecer é preciso a ação. Para ele a ação vai além do fazer mecanicista, pois há uma reflexão. A reflexão-na-ação diferencia-se de outras reflexões, pois dá-se significação imediata na ação. Assim, se o professor formador usar a reflexão na prática pedagógica fazendo uso da TCD estará agregando conhecimento para si e para seus discentes, pois estará conectando a ação com a reflexão e possibilitando a experiência de novas formas de ofertar situações de aprendizagem.

O professor formador é um "arcabouço" constituído pelo pensar, agir e o refletir, e neste caminho de idas e vindas usa de seus conhecimentos técnicos e também pessoais para analisar suas ações pedagógicas, utilizando saberes prévios e estruturando novos. Por isso, a reflexão é uma peça chave para, com base nela, ocorrer uma avaliação da prática docente e ampliá-la por meio de uma constante transformação e formação. Desse modo, para Schön (2000), o professor formador repensa sua prática, a partir do seu conhecimento da ação, reflete sobre ela, de modo a promover as mudanças necessárias ao seu fazer pedagógico.

A TCD vem, também, ao encontro desta ação reflexiva e soma-se às ações pedagógicas necessárias e que podem despertar novos fazeres na formação de professores. Para tanto, a formação docente deve ser "cada vez mais atrelada a uma prática profissional múltipla, exigindo-se cursos ainda mais completos e concisos com às demandas da sociedade" (SIQUEIRA; MOLON; FRANCO, 2018, p. 2).

Considera-se, portanto, que a educação deve alinhar-se ao uso da TCD a partir de um olhar crítico e ressignificado por parte dos professores formadores, pois esses estarão refletindo não somente utilizando a TCD como recurso, mas como uma forma de integralizar a formação do futuro discente como um profissional mais condizente com a atualidade e capaz de transformar-se de forma constante e inovadora.

\section{Percurso Metodológico}

A presente pesquisa de caráter qualitativo procurou responder à seguinte questão: Como o docente formador utiliza a TCD na formação inicial de professores, no intuito de 
oportunizar formação, reflexão e conhecimento para as futuras práticas pedagógicas desses sujeitos? A análise que segue ampara-se em 11 respostas, sendo 5 de professores do curso de Licenciatura em Letras - Português/Inglês e 6 do curso de Licenciatura em Matemática. Utilizou-se como abordagem de investigação a análise de conteúdo, compreendida como um:

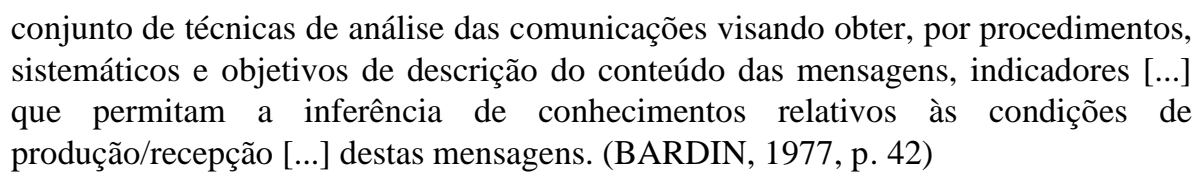

Dessa forma, as respostas dos professores foram agrupadas no decorrer da análise, a partir de dados que compartilham algumas características, procurando compreender o conjunto de mensagens apresentadas em cada uma das questões elencadas. Optou-se por expor a discussão dessa forma, a fim de possibilitar ao leitor a análise sequencial do estudo, bem como compreender as controvérsias que foram identificadas através dessa abordagem.

\section{Análise de Dados e Resultados}

A análise dos dados deu-se por meio de uma leitura interpretativa, trazendo considerações e apontamentos pertinentes com o embasamento teórico para cada uma das perguntas. Por questão ética, ao fazer referência a cada um dos 11 docentes participantes da pesquisa utilizou-se a seguinte codificação: P1, P2, P3, P4, P5, P6, P7, P8, P9, P10 e P11.

A figura 1 contém os questionamentos que foram realizados e que orientam essa seção. Pode-se observar que algumas perguntas entrelaçam-se, propositalmente, pensou-se em apresentá-las dessa forma e uma a uma, justamente para cruzar e, assim, verificar as declarações de cada docente nas diferentes questões. Através dessa estratégia conseguimos, além de responder ao questionamento orientador do estudo, também identificar algumas controvérsias, as quais também serão exploradas. Observa-se, no entanto, que essas não se referem de forma exclusiva à dicotomia teoria e prática, mas trazem aspectos relacionados às políticas públicas de formação docente, a investimentos em infraestrutura das escolas e ao próprio perfil dos estudantes matriculados nos referidos cursos. 


\begin{tabular}{|c|l|}
\hline $\begin{array}{c}\text { Pergunta } \\
\mathbf{1}\end{array}$ & $\begin{array}{l}\text { Você utiliza ferramentas tecnológicas digitais nas aulas que ministra em cursos de formação } \\
\text { inicial de professores? Se sim, como o faz? Se não, explique o(s) motivo(s). }\end{array}$ \\
\hline $\begin{array}{c}\text { Pergunta } \\
\mathbf{2}\end{array}$ & $\begin{array}{l}\text { Você considera necessário ao planejar suas aulas, para os futuros professores, integrar os recursos } \\
\text { tecnológicos digitais como estratégias de ensino-aprendizagem? Explique. }\end{array}$ \\
\hline $\begin{array}{c}\text { Pergunta } \\
\mathbf{3}\end{array}$ & $\begin{array}{l}\text { Na sua opinião, qual o papel das Tecnologias de Comunicação Digital na formação inicial de } \\
\text { professores? }\end{array}$ \\
\hline $\begin{array}{c}\text { Pergunta } \\
\mathbf{4}\end{array}$ & $\begin{array}{l}\text { Provavelmente os discentes de cursos de formação inicial de professores, em sua maioria, são } \\
\text { Nativos Digitais, ou seja, já dominam os recursos tecnológicos. Como a utilização desses recursos } \\
\text { poderia melhor prepará-los para suas futuras práticas enquanto professores? }\end{array}$ \\
\hline $\begin{array}{c}\text { Pergunta } \\
\mathbf{5}\end{array}$ & $\begin{array}{l}\text { Segundo a sua prática docente, o que esse discente em formação precisa para em sua futura prática } \\
\text { pedagógica ser capaz de utilizar as tecnologias em suas aulas de maneira positiva e } \\
\text { potencializadora da aprendizagem? }\end{array}$ \\
\hline $\begin{array}{c}\text { Pergunta } \\
\mathbf{6}\end{array}$ & $\begin{array}{l}\text { Sabe-se que nas ementas, muitas vezes, não consta tudo que realmente é desenvolvido nas aulas } \\
\text { com os discentes. Assim, você considera que as questões de práticas docentes com o apoio das } \\
\text { tecnologias digitais deveriam ser inseridas em mais ementas? Justifique. }\end{array}$ \\
\hline
\end{tabular}

Figura 1 - Apresentação do Questionário

Fonte: elaborado pelos autores.

Quando questionados sobre a utilização de tecnologias, na pergunta 1, para alguns professores, fica claro o uso da TCD apenas como mudança do meio, mas não da forma. Quando citam o uso da internet para realização de exercícios de gramática ou vocabulário (P7), ou quando usam apresentações de powerpoint (P8; P3). No entanto, o uso da tecnologia por si só não altera a prática. O uso da TCD na educação deve oferecer espaço para que o estudante seja ativo no seu processo de construção de conhecimento, não mais um receptor passivo (ROJO, 2017).

Outros participantes apontaram que além de práticas mais comuns e de transmissão do conhecimento, exploram outras potencialidades da TCD, como: o uso do Google Drive 6 como meio de promover práticas colaborativas (P10; P9); solicitam pesquisas na rede (P5; $\mathrm{P} 1)$; propõe tarefas de elaboração de sites/blogs (P4); realizam práticas com o gênero vídeo, que faz parte da cultura digital (P1; P5); exploram ferramentas, softwares disponíveis na rede que podem auxiliar, de alguma maneira, os processos de ensino e aprendizagem (P1; P11; P8), de redes sociais e aplicativos (P1) e de softwares como o Geogebra ${ }^{7}$ (P5; P4).

A maioria dos docentes entrevistados relatou que o Moodle 8 é uma das ferramentas utilizadas na formação de professores (P3; P2; P4; P5; P8; P9; P10). A questão, por sua vez, é

\footnotetext{
${ }^{6}$ Google Drive é um serviço de armazenamento e sincronização de arquivos (gsuite.google.com/intl/pt-BR/products/drive/)

${ }^{7}$ Geogebra é um software de matemática dinâmica, livre e mutiplataforma (geogebra.org/).

${ }^{8}$ Moodle é um Ambiente Virtual de Aprendizagem que é utilizado na instituição em que a pesquisa foi realizada.
} 
como o fazem, sendo que muitos deixam claro que o utilizam como repositório de textos e listas de exercícios. P4, no entanto, relata a utilização do Moodle e outras ferramentas digitais "com viés instrumental ao futuro docente discutindo (elaborando práticas) sobre a utilização desse recurso na prática desse profissional e o potencial que aprender com tecnologias pode proporcionar". Dessa forma, P4 está possibilitando a ação para que a reflexão aconteça e, assim, permita ressignificar sua prática docente, o que poderá refletir na sua futura prática pedagógica (SCHÖN, 2000).

Apenas P6 disse não usar TCD em suas práticas e justificou: "Como a natureza destas disciplinas é mais sobre de iniciá-los no estudo acadêmico da literatura, acaba não havendo muito espaço para discussão sobre a questão pedagógica em si”. Não se trata somente de ensinar sobre TCD nos processos educativos, mas de usar como ferramenta para alcançar objetivos de ensino e aprendizagem e, logo, proporcionar referências aos futuros professores.

Ao serem questionados, na pergunta 2, se consideram necessário, ao planejar aulas para os futuros professores, integrar os recursos tecnológicos digitais como estratégias de ensino e aprendizagem, todos responderam que sim. Entre as respostas, os professores exaltam os pontos positivos de inserir a TCD nas aulas, pontuam que possibilitam novas aprendizagens (P1) e desenvolvimento de trabalhos colaborativos (P5; P10). P8 e P10 destacam ser necessário integrar as tecnologias, pois elas estão presentes no cotidiano. Dessa maneira podemos oferecer práticas condizentes com a sociedade da informação na qual vivemos, que, conforme Coll e Monereo (2010, p. 15), possui novas características, "novas maneiras de trabalhar, de comunicar-se, de relacionar-se, de aprender, de pensar e, em suma, de viver" e, assim, demanda diferentes práticas.

P5 ressalta, ainda, a necessidade de "provocar uma reflexão crítica e questionadora em relação à busca e elaboração da informação", o que vai ao encontro de Ludovico e CostaBarcellos (2019), quando explicam que a formação deve proporcionar reflexão, permitir (re)pensar, questionar práticas e crenças. P4 e P9 também julgam fundamental promover reflexões sobre usos e potencialidades das tecnologias.

P11 enfatiza "a questão da integração desses recursos às aulas, não tomando-os como a única ou a melhor possibilidade”, e nesse mesmo sentido, P2 acredita que talvez uma "mescla de aulas com intenso uso de recursos digitais, aulas com uso moderado e aulas sem utilização de recursos digitais seja uma boa estratégia e isso requer planejamento". O novo precisa ser considerado, mas isso não significa deixar de lado o legado do passado, apenas os 
papéis mudam (PRENSKY, 2010). Assim, torna-se necessário olhar sob um diferente ponto de vista e repensar nossas práticas.

As respostas de P4, P5 e P10 também evidenciam que os próprios professores formadores não foram formados para usar a TCD, pois apontam que falta familiaridade (P10; P5) e referências, experiências com tais recursos (P4). Esses apontamentos fazem compreender que as ações de ênfase à incorporação de orientações e normativas acerca do uso da TCD nas DCN para a formação inicial de professores, por exemplo, são necessárias.

De todo modo, na pergunta 3, em relação ao papel da TCD na formação inicial de professores, é unânime para os participantes da pesquisa a compreensão de que o seu uso pode contribuir tanto nos processos de ensino, quanto nos processos de aprendizagem. Os professores entrevistados reconhecem o potencial de uso da TCD para além da sua função instrumental, o que vai ao encontro do publicado nas novas DCN, bem como atendem às demandas que constam na BNCC.

De acordo com P4, as tecnologias "se apresentam como um recurso potencial para auxiliar na formação, servindo como fonte de informação e construção de conhecimentos. Bem como, auxiliar na individualização da aprendizagem e os ampliar (sic) recursos e estratégias que o mesmo poderá ter para utilizar na sua prática profissional”. Essa concepção aproxima-se do objetivo central da práxis pedagógica frente ao cenário de avanço tecnológico, que, conforme Pérez Gómez (2015), refere-se a auxiliar os estudantes a se educarem.

Argumentando nesse sentido, P9 escreveu que compreende no mínimo dois papéis que a tecnologia desempenha na fase inicial da formação docente: "O primeiro é melhorar o seu próprio aprendizado [...]. O segundo é que consigam desenvolver atividades pedagógicas em sintonia com o mundo dos alunos, cada vez mais digital”. Nessa direção, entre os papéis da tecnologia na formação inicial de professores também se destacou, na pesquisa, a sua utilização como recurso ou ferramenta para efetivação de um objetivo pedagógico, que pode auxiliar os processos de ensino e aprendizagem (P1; P2; P11).

Outro aspecto citado foi a possibilidade de promover engajamento docente visando "o desenvolvimento da consciência cidadã dos seus futuros alunos" (P7) e "desenvolvendo o pensamento crítico, a criatividade e a originalidade", considerando a chegada da era digital (P5). Pelo fato de os estudantes estarem cada vez mais integrados à TCD, o acompanhamento do avanço tecnológico e, portanto, a necessidade de integração da TCD nas suas futuras práticas de ensino também foram argumentos trazidos por alguns docentes (P3; P5; P6; P8). 
Isso vai ao encontro das necessidades de formação para a integração tecnológica contempladas na Base Nacional Comum para a Formação Inicial de Professores da Educação Básica (BNC-Formação), publicada em dezembro de 2019.

No entanto, critérios semelhantes aos exigidos para a formação inicial de professores "devem ser exigidos com mais intensidade na formação e atuação dos formadores de docentes" (PÉREZ GÓMEZ, 2015, p.149). A resposta fornecida por P10 defendeu que as tecnologias deveriam exercer um papel importante, tendo em vista o espaço que elas ocupam na vida das pessoas, mas salienta um desafio a ser superado: "barramos no fato de os formadores de professores não terem tido esse foco em sua formação, como é o meu caso" (P10), aspecto também destacado nas respostas ao questionamento anterior.

Outro desafio a ser superado refere-se à infraestrutura: "Além de as escolas não estarem, ainda em 2020, equipadas com computadores ou wifi público" (P10). Pode-se apoiar essa afirmação nos dados do relatório TIC Educação 2018 (CGI.br, 2019). Em 2018, 55\% das escolas rurais não tinha internet e apenas $57 \%$ das escolas públicas urbanas possui internet disponível na sala de aula, sendo que em $66 \%$ dessas a rede WiFi é protegida por senha não acessível aos alunos. A partir desses e outros dados, a mesma pesquisa ainda destaca que a infraestrutura é um obstáculo para um uso efetivo das tecnologias nas escolas.

Um aspecto que é importante ressaltar, contudo, é o de que muitas vezes, mesmo compreendendo e valorizando as contribuições que a TCD pode trazer à educação, percebe-se que isso não reflete na prática da totalidade dos professores. Assim, embora a maioria faça tentativas de integração da tecnologia em suas aulas, estando em processo de desenvolvimento, muitos ainda utilizam a TCD apenas como instrumento (para projetar slides, por exemplo). Outros, no entanto, afirmam a importância e dão créditos à TCD nos processos educativos, mas justificam o seu não uso em função de características específicas dos conteúdos de algumas disciplinas, conforme já analisado anteriormente (Pergunta 1). De acordo com Pérez Gómez (2015), esses aspectos merecem atenção, uma vez que é difícil estimular o desenvolvimento de capacidades nos futuros docentes se estas são negadas ou não foram desenvolvidas pelos próprios professores formadores.

Os entrevistados responderam também, na pergunta 4, acerca de como a utilização de recursos tecnológicos poderia melhor prepará-los para suas futuras práticas enquanto professores, considerando que, provavelmente, os discentes de cursos de formação inicial de professores, em sua maioria, são Nativos Digitais (PRENSKY, 2001; 2010). Todas as 
respostas apresentam argumentos a favor da utilização e da discussão sobre formas de uso TCD ao longo da formação docente e salientam sobre os possíveis usos, mesmo que em diferentes realidades em que os futuros professores venham a atuar, "levando em consideração que muitas escolas, infelizmente, não possuem recursos tecnológicos, [...] nós como formadores devemos indicar o caminho aos futuros docentes" (P1).

De modo geral, destacou-se que os recursos tecnológicos podem ser utilizados como forma de diversificar e dinamizar as práticas de ensino e de aprendizagem (P2; P3; P7; P8; $\mathrm{P} 11)$, aproximando os docentes dos alunos (P10) ou atraindo os estudantes para as aulas (P3; P6; P8). Podem promover trabalho colaborativo (P5), possibilitar acesso e socialização das informações (P2; P9) e a novas culturas e realidades (P6). Podem auxiliar no “desenvolvimento da consciência cidadã dos seus alunos" (P5; P7), na criatividade (P5) e como forma de preparação dos licenciandos para "lidar com seus futuros alunos em plataformas digitais" (P9), uma vez que "muitos alunos da escola básica já têm acesso a esses recursos e estes, sim, parecem ser Nativos Digitais (em sua maioria)" (P11).

Alguns professores discordam da afirmação acerca da maioria dos professores em formação dos cursos onde atuam serem Nativos Digitais (P1; P3; P11). Argumentam que os alunos possuem diferentes faixas etárias (P1; P11) e, além disso, mesmo que sejam assim denominados, diferem também quanto ao acesso a esses recursos (P11) e ao tipo de uso que fazem deles (P4; P10). Nesse sentido, P4 escreveu que o "domínio de recursos tecnológicos dos mais jovens geralmente está estritamente relacionado a especificidade ou familiaridade das ferramentas ou recursos de comunicação, como as redes sociais ou outro recurso que ele utiliza no seu dia-a-dia e dentro das suas demandas. Ferramentas básicas de um computador, como editor de texto, planilhas ou apresentação, nem sempre são conhecidos”. Nesse sentido, se os professores em formação inicial são Imigrantes Digitais (PRENSKY, 2001), é ainda mais relevante possibilitar práticas com a TCD, multiletramentos, com o objetivo de preparar esses sujeitos para atuar na SI, pois como afirmado por P11, possivelmente a maioria de seus estudantes serão Nativos Digitais.

Assim, muitas vezes, mesmo que os estudantes tenham acesso aos recursos tecnológicos, seu uso fica restrito a poucas ações. P10 acredita que "o mau uso das tecnologias ainda seja seu principal uso. Redes sociais, aplicativos de fotos e de mensagens instantâneas são as ferramentas utilizadas. Ainda os computadores e smartphones são muito pouco utilizados para a produção de conhecimento". Nessa direção, P4 propõe que, talvez 
"discutir sobre o tempo que se gasta com as redes sociais, a postura que muitos adotam no ‘mundo' virtual e a exposição que assumem seja importante”.

A constituição da identidade do professor exige uma formação contínua, a qual não pode ser compreendida como mera aplicação de conhecimentos técnicos. Deve-se entender que a prática do ser professor possui embasamento teórico constituindo conhecimentos específicos na sua área de formação e ainda, deve ser acrescida de criticidade, de ética e de comprometimento com o processo de ensinar, o qual deve acompanhar a evolução e demanda social, tais como o uso das tecnologias nos processos de ensino e aprendizagem.

$\mathrm{Na}$ sequência, questionou-se (pergunta 5) acerca do que os professores formadores estão exercendo em sua prática docente de modo a contribuir para os discentes em formação, e o que segundo eles faz-se necessário para uma futura prática pedagógica ao utilizar-se das tecnologias, pois considera-se possível através do uso dessas desenvolver aulas de maneira positiva e potencializadora da aprendizagem.

Diante dessas considerações apresenta-se a reflexão de P5: “conhecer o processo de aprendizagem quanto as suas finalidades e à sua abrangência, conhecer estratégias inovadoras utilizando as mais diversas ferramentas disponíveis a fim de torná-lo capaz de desenvolver atividades em sua sala de aula, transformando as tecnologias em oportunidades de aprendizagem”. Logo, no que tange à ação docente na atualidade, deve-se oportunizar o ensino de maneira diversificada, conciliando esse processo ao interesse dos futuros professores e adequando com o que hoje se tem como inovação tecnológica, assim despertando uma formação mais contextualizada e condizente com a necessidade educacional de aprendizagem. Corroborando com essa reflexão tem-se Schön (2000), o qual considera que na carreira do professor formador esse deve repensar sua prática em face do fazer docente, possibilitando mudanças na compreensão desse fazer e a ação em si. Desse modo, este movimento repercutirá na prática pedagógica em relação ao futuro professor, ou seja, ambos na ação pedagógica irão se abastecer com a inovação e (re)significar por meio do uso da tecnologia.

Nos dias atuais a inovação no campo da TCD é crescente e necessita ser mais utilizada na educação, logo conhecer ferramentas e saber selecioná-las de acordo com a proposta educacional a qual se quer é imprescindível, pois assim se estará mediando objetivos de ensino com uma efetiva formação docente. De acordo com essa ponderação, considera-se o que P7 relatou: "diante da enorme quantidade de recursos e conteúdos digitais disponíveis, o 
discente em formação precisa aprimorar sua capacidade de avaliação crítica das tecnologias, somente assim será capaz de selecionar o que for mais relevante para os seus alunos e a sociedade no qual estão inseridos".

Conforme aborda a BNCC (BRASIL, 2018), em relação à TCD, essa deve-se fazer presente na prática pedagógica, ou seja, esse documento apresenta que ao utilizar-se das tecnologias se fomentará uma formação mais abrangente, proporcionando aos discentes em formação competências éticas, reflexivas e críticas. Assim, terão oportunidades de serem protagonistas de sua formação. Para isso, os futuros profissionais da educação poderão direcionar suas ações docentes tendo como base as experiências e o que vivenciaram enquanto discentes e ao terem utilizado ferramentas que possam dar um suporte como recursos pedagógicos, poderão beneficiar o aprendizado dos seus educandos, independente da etapa educacional.

Com base na contribuição de P9. os alunos "precisam de incentivo e liberdade para fazerem práticas de ensino com a adoção de tecnologias. É importante que o professor regente fique aberto para ouvir dos alunos sugestões de tecnologias a serem adotadas". Compreendese que os discentes devem ter autonomia, mas a iniciativa e o exemplo devem ser do docente formado. Na prática de sala de aula ao usar tecnologia não apenas como suporte mas, também, como inovação e como maneira de despertar o interesse dos educandos se estará permeando uma futura práxis, através de exemplos e a vivências.

Ratificando a necessidade de se ter a tecnologia presente nos anos de formação docente, tem-se a consideração de P11: "minha experiência me mostra dois pontos fundamentais - o discente deve ter tido contato durante o curso de graduação com a questão integrada do uso de TICs na sala de aula (o que é, como fazer e qual a importância das tecnologias); e estes recursos devem estar disponíveis para o uso do aluno (em funcionamento pleno) tanto no curso de formação inicial quanto no ambiente escolar em que o aluno irá atuar (...)”. P11 ainda enfatiza a importância de propiciar contato, experiências e discussões sobre a TCD com os professores em formação, trazendo para seu contexto de formação a reflexão sob a ação, segundo nos aponta Schön (2000). No que se refere a ter esses recursos disponíveis no ambiente em que irá atuar, não há como saber onde e quais serão as condições dos futuros locais de trabalho. Assim, faz-se necessário oferecer práticas de multiletramentos, propiciando referências, para os futuros professores, pois tudo isso fará parte de sua bagagem, da constituição do ser professor. 
Neste cenário, agregar a utilização da TCD na formação de professores é oportunizar uma educação além do tradicional, é fomentar uma formação mais integral, atrelando interesses, demandas sociais e variadas formas de interação e comunicação em busca de uma educação mais real e plena, pois fora das "paredes da sala de aula" a sociedade exige um profissional atualizado, proativo e inovador. Isso se vincula à posição de Rojo (2017), em relação às práticas e suas maneiras de serem mais autênticas e condizentes, viabilizando multiletramentos.

Por fim, sabendo que nas ementas muitas vezes não constam tudo o que é desenvolvido nas aulas com os discentes, questionou-se, na pergunta 6 , se eles consideram que assuntos de práticas com apoio da TCD deveriam ser inseridos em mais ementas. Nesta perspectiva, acrescenta-se a ótica do $\mathrm{P} 4$, que se refere à importância da "concepção e o entendimento que se está dando as tecnologias digitais, que esteja claro no PPC e o viés tecnológico que a formação vai assumir ser reforçada e alinhada frequentemente, senão cada um seguirá no seu modus operandi usando ou integrando tecnologias a sua maneira”.

Assim, compreende-se que o fundamental é conciliar a proposta pedagógica com um olhar reflexivo e inovador que contribua na formação docente, contemplando uma conexão entre a atuação do docente formador com a atual realidade e a necessidade de formar um futuro professor focado em práticas diversificadas. Dessa forma, tais ações podem vincular o ensino segundo os interesses dos educandos, bem como atingir formas de aprendizagem mais dinâmicas e reflexivas, contribuindo para um ensino mais autêntico. Para tanto, é preciso promover diálogos e reflexões junto aos formadores, de modo que as instituições de ensino possam dar autonomia e incentivo aos seus professores, além de prover recursos materiais necessários para o desenvolvimento de uma prática pedagógica produtiva e potencializadora.

Corroborando com este debate, tem-se o pensamento de P4, o qual aponta que "o curso deveria criar algum espaço de discussão para aproximar ou alinhar/conhecer as diferentes práticas que já estão sendo feitas pelos professores. Conhecer os diferentes perfís e a partir daí ver a viabilidade do ponto de vista dos recursos humanos e tecnológicos existentes naquele momento e de quais práticas e qual enfoque é importante a ser seguido. Somente inserir nas ementas é um caminho complicado, pois se a forma como é pensada a tecnologia não é discutida e (re)significada, o seu entendimento ou uso poderá, quando feito, ser bem distinto do pensado ou proposto na ementa". Nesse sentido, cabe ao grupo de formadores ajustar um caminho a ser seguido e estruturado na formação de professores através do uso de 
TCD, uma vez que se considera insuficiente apenas indicar, apontar ferramentas, pois a ação e o fazer estarão distantes para a vivência e a experiência. Logo, para se promover um caminho de ensino e aprendizagem mais coerente, reflexivo e construtivo, a TCD deve ser incorporada para além de um instrumento e deve ser associada à constituição da identidade docente, visto que permeará uma formação diferenciada e inovadora aos futuros professores.

Constatou-se, após a análise, alguns itens que configuram controvérsias, as quais serão apresentadas na seção final. Além disso, diante das considerações tratadas, percebe-se a necessidade de maior reflexão e diálogos referentes à concepção do uso da TCD na formação de professores. Acredita-se que de forma conjunta e por meio do amparo do PPC deve-se acrescentar a TCD no âmbito educacional, fomentando espaços de produção a favor do desenvolvimento de competências. Ou seja, ofertar uma formação diferenciada aos futuros professores, de modo que discentes e docentes possam ressignificar a prática pedagógica de forma mais coerente e potencializadora para os processos de ensino e aprendizagem.

\section{Considerações Finais}

A formação de professores precisa rever a abordagem que desenvolve junto às tecnologias, uma vez que o uso dessas faz parte do cotidiano de todos. A justificativa de que os docentes não se sentem aptos a usá-las mostra duas situações: que há uma lacuna na formação dos próprios formadores, ou seja, as instituições formadoras não estão trabalhando a TCD e seu uso relacionando-a aos conteúdos; e, ainda, como segundo ponto, que existe um distanciamento entre os cursos de formação inicial de professores e a demanda da Sociedade da Informação (SI).

Pensar numa concepção de educação que dê o aporte junto à formação global e atual de professores, buscando relacionar o hoje junto a metodologias de uma prática de ensino dinâmico e condizente aos interesses, é trazer o uso da TCD para a formação, com o intuito de possibilitar que essas sejam usadas efetivamente nas práticas escolares para a promoção de construção de conhecimento pelos estudantes.

Contudo, compreende-se que se trata de um processo, e ações têm sido realizadas para mudanças nesse cenário, como proposições ou alterações em documentos normativos, a exemplo da BNCC, e mais recentemente as DCN, as quais orientam os cursos de licenciatura e passaram a exigir explicitamente mudanças nesse sentido.

A partir dos dados verificaram-se controvérsias: 
- Os docentes têm consciência dos motivos para usar TCD e a utilizam como recurso em algumas práticas de ensino. No entanto, nem sempre acontecem momentos de discussão e reflexão sobre o uso e relevância da TCD a fim de propiciar embasamento teórico-prático aos futuros professores.

- Acreditar que a TCD só pode ser inserida em determinadas disciplinas ou que devam existir disciplinas específicas para se trabalhar com TCD.

- Julgar que só se deve ensinar sobre TCD caso o futuro professor tenha essas a sua disposição. Essa afirmação traz um paradoxo, uma vez que a TCD muda com certa rapidez e o uso de determinada tecnologia pode tornar-se obsoleto em pouco tempo. Além disso, não há como saber quais recursos esses sujeitos terão disponíveis em suas futuras atuações.

- Embora os professores formadores possam não ter tido essa formação direcionada, é importante estar em contínua formação para se atualizar e prover práticas condizentes e necessárias para os futuros professores.

Diante da análise realizada, essas controvérsias indicam aspectos acerca da prática pedagógica exercida pelos docentes formadores. Dessa maneira, reforça-se no âmbito educacional a carência de mais diálogo, (re)construção coletiva de concepções e reflexões sobre a própria ação e a necessidade de formação do futuro professor frente a SI e a TCD. Para tanto, as instituições responsáveis pela formação inicial de professores têm a incumbência de possibilitar tais momentos, para que a integração da TCD tenha um reflexo significativo.

Destaca-se que através das respostas dos questionários foi possível, também, identificar práticas relevantes com uso da TCD, as quais visam dar espaço para sujeitos ativos - característica essencial no processo de constituir-se professor, além de evidenciar a utilização de materiais autênticos, fortalecendo os processos de ensino e aprendizagem. Ainda, o estudo revelou preocupações em relação à promoção de interação por meio da TCD, práticas que além de possibilitar multiletramentos, contribuem para o desenvolvimento de competências imprescindíveis à Sociedade da Informação.

\section{REFERÊNCIAS}

BARDIN, Laurence. Análise de conteúdo. Lisboa: Edições 70, 1977.

BRASIL. Base Nacional Comum Curricular: Ensino Médio. Brasília: MEC/Secretaria de Educação Básica, 2018.

BRASIL. Ministério da Educação. Conselho Nacional de Educação. Conselho Pleno. 
Resolução n² de 2019. Disponível em: <

http://portal.mec.gov.br/docman/dezembro-2019-pdf/135951-rcp002-19/file>. Acesso em: mar./ 2020.

COMITÊ GESTOR DA INTERNET NO BRASIL (CGI.br). Pesquisa sobre o uso das tecnologias de informação e comunicação nas escolas brasileiras - TIC Educação 2018. [livro eletrônico] / Núcleo de Informação e Coordenação do Ponto BR. São Paulo: Comitê Gestor da Internet no Brasil, 2019. Disponível em:

<https://cetic.br/pesquisa/educacao/publicacoes> Acesso em: fev./2020.

COLL, César; MONEREO, Carles. Educação e aprendizagem no século XXI: novas ferramentas, novos cenários, novas finalidades. In: COLL, Cesar; MONEREO, Carles. Psicologia da educação virtual: aprender e ensinar com as tecnologias da informação e da comunicação. Porto Alegre: Artmed, 2010.

EADY, Michelle; LOCKYER, Lori. Tools for learning: technology and teaching strategies. In: HUDSON, Peter (Ed.) Learning to Teach in the Primary School. Queensland: Queensland University of Technology, 2013, p. 71-89.

KENSKI, Vani M. Educação e Internet no Brasil. Cadernos Adenauer, São Paulo, XVI, n. 3, p. 133-150, 2015.

LUDOVICO, Francieli; BARCELLOS, Patrícia. S. C. C.. Momentos de reflexão docente frente à sociedade da informação: inventividade e produção de subjetividades. Tear: Revista de Educação, Ciência e Tecnologia, v. 8, p. 1-10, 2019.

PÉREZ GÓMEZ, Angel. I. Educação na era digital: a escola educativa. Porto Alegre: Penso, 2015.

PRENSKY, Marc. Digital Natives, Digital Immigrants. MCB University Press, Vol. 9 No. 5, October, 2001.

PRENSKY, Marc. Partnering. Teaching digital natives. Partnering for real learning.

Thousand Oaks, CA: Corwin Press, 2010.

ROJO, Roxane. Entre Plataformas, ODAS e Protótipos: Novos Multiletramentos em Tempos de WEB2. The ESPecialist: Descrição, Ensino e Aprendizagem, São Paulo, Vol. 38 No. 1, p. 1-20, jan-jul, 2017.

SIQUEIRA, Claudiomir; MOLON, Jaqueline; FRANCO, Sérgio. Integração das tecnologias digitais para exploração e desenvolvimento do raciocínio visuoespacial na aprendizagem de geometria. Renote: Revista Novas Tecnologias na Educação, v. 16, p. 1, 2018.

SCHÖN, Donald, A. Educando o profissional reflexivo: um novo design para o ensino e a aprendizagem; trad. Roberto Catoldo Costa - Porto Alegre: Artmed, 2000.

Recebido em: 26/5/2020 Aceito em: 26/5/2020 